\title{
O PIBID NA FORMAÇÃO DOS LICENCIANDOS EM QUÍMICA DO IFTM - CAMPUS UBERABA: (RE)PENSANDO A DOCÊNCIA NA EDUCAÇÃO BÁSICA
}

\author{
A. K. PEREIRA* e G. G. LIMA \\ Instituto Federal de Educação, Ciência e Tecnologia do Triângulo Mineiro - Campus Uberaba \\ alanakelyene@live.com*
}

Artigo submetido em outubro/2015 e aceito em abril/2016

DOI: $10.15628 /$ holos.2016.3489

\section{RESUMO}

O Programa Institucional de Bolsa de Iniciação à Docência é uma iniciativa da Capes que visa a valorização, o incentivo à docência a inserção dos licenciandos no cotidiano de escolas da rede pública. O Pibid IFTM iniciou suas atividades em 2011, com subprojetos na área de Química, Ciências Biológicas, Ciências Sociais e Computação. O presente trabalho teve como objetivo geral analisar as influências das atividades desenvolvidas no Pibid subprojeto de Química (entre 2011 e 2013) para a formação do futuro professor, entre os estudantes bolsistas do curso de Licenciatura em Química do IFTM, Campus Uberaba. A pesquisa foi realizada com abordagem quanti-qualitativa, incluindo a coleta de dados e a análise de respostas aos questionários disponibilizados on-line pela ferramenta Google Drive. A análise dos dados discursivos foi organizada por categorias diante das similitudes de opiniões. Os resultados da pesquisa evidenciam as transformações que o programa vem causando na vida dos participantes do Pibid, colaborando para a melhoria da formação pessoal, cidadã e acadêmica dos licenciandos em Química. Verificou-se que a maioria dos objetivos do programa foram efetivados, com destaque para a inserção dos licenciandos no cotidiano das escolas conveniadas da Educação Básica. Mas, ressalta-se a importância de um constante processo de revisão e de atualização estratégica, tática e operacional para que os efeitos do programa sejam ainda mais significativos, a médio e longo prazo.

PALAVRAS-CHAVE: Formação inicial e continuada, iniciação à docência, Licenciatura em Química, Pibid.

\section{THE PIBID IN TRAINING IN CHEMICAL UNDERGRADUATES OF IFTM - CAMPUS UBERABA: (RE)THINKING THE TEACH IN BASIC EDUCATION}

\begin{abstract}
The Institutional Program of Initiation to Teaching is a initiative from Capes which aims appreciation and encouragement to teaching and the inclusion of undergraduates in reality of public schools. The Pibid IFTM began in 2011 with subprojects in Chemistry, Biological Sciences, Social Sciences and Computer Science. This study has the goal to analyze the influence of activities in the Pibid Chemistry subproject (from 2011 to 2013) for the formation of the future teacher among the Chemistry undergraduate students of IFTM, Campus Uberaba. The research was conducted with quantitative and qualitative approach, including data collection and analysis of responses to questionnaires available online through Google Drive tool. The analysis of the discursive
\end{abstract}

data was organized in different categories according to the similarities of views. The results show the changes that the program has caused in the lives of participants, contributing to the improvement of personal and academic training of undergraduates in chemistry. It was found that most of the program's objectives were accomplished, especially the inclusion of undergraduates in the reality of the accredited schools of basic education. But it emphasizes the importance of a constant process of revision and update of strategic, tactical and operational for the purposes of the program are even more significant, considering its effects in the medium and long term.

KEYWORDS: Initial and continuing education, introduction to teaching, Graduation in Chemistry, Pibid. 


\title{
1 INTRODUÇÃO
}

O Programa Institucional de Bolsa de Iniciação à Docência (Pibid) é uma iniciativa da Capes que visa a valorização e o incentivo à docência, aliando estudantes dos cursos de licenciaturas das instituições de ensino superior com a rede básica de ensino público. De acordo com o portal do programa MEC/Capes - Pibid, os objetivos do programa consistem em:

- Incentivar a formação de docentes em nível superior para a Educação Básica;

- Contribuir para a valorização do magistério;

- Elevar a qualidade da formação inicial de professores nos cursos de licenciatura, promovendo a integração entre Educação Superior e Educação Básica;

- Inserir os licenciandos no cotidiano de escolas da rede pública de educação, proporcionando-lhes oportunidades de criação e participação em experiências metodológicas, tecnológicas e práticas docentes de caráter inovador e interdisciplinar que busquem a superação de problemas identificados no processo de ensino-aprendizagem;

- Incentivar escolas públicas de Educação Básica, mobilizando seus professores como coformadores dos futuros docentes e tornando-as protagonistas nos processos de formação inicial para o magistério; e

- Contribuir para a articulação entre teoria e prática necessárias à formação dos docentes, elevando a qualidade das ações acadêmicas nos cursos de licenciatura (BRASIL, 2008).

O Pibid proporciona ao futuro docente a vivência no ambiente escolar, por meio do espaço e de oportunidades para o estudante de licenciatura buscar meios de colaboração para a qualidade da educação nas escolas públicas e fundamentação de sua formação acadêmica como docente.

Conforme Guimarães (2014), a Capes estimula a excelência e a equidade e, por isso, auxilia em programas de desenvolvimento científico e acadêmico, buscando a qualidade na formação dos professores com propostas inovadoras, sendo uma necessidade intrínseca na sociedade atual. Com a publicação do primeiro edital de seleção de propostas do Pibid, em 2007, o programa traduziu de forma inequívoca os princípios e o compromisso da Capes com a formação de professores. Assim,

\begin{abstract}
O Programa Institucional de Bolsas de Iniciação à Docência (Pibid) traduz de forma inequívoca os princípios e o compromisso da Capes com a formação de professores. Iniciando em 2009 com 3.088 bolsistas e 43 instituições federais de ensino superior, em 2014, o Pibid alcançou 90.254 bolsistas, distribuídos em 855 campi de 284 instituições formadoras públicas e privadas (em 29 delas há também programas para as áreas da educação escolar indígena e do campo). O Pibid, contudo, não é simplesmente um programa de bolsas. É uma proposta de incentivo e valorização do magistério e de aprimoramento do processo de formação de docentes para a educação básica. Os alunos de licenciatura exercem atividades pedagógicas em escolas públicas de educação básica, contribuindo para a integração entre teoria e prática, para a aproximação entre universidades e escolas e para a melhoria de qualidade da educação brasileira. Para assegurar os resultados educacionais, os bolsistas são orientados por coordenadores de área - docentes das licenciaturas - e por supervisores - docentes das escolas públicas onde exercem suas atividades. (GUIMARÃES, 2014, p. 5)
\end{abstract}


Diante disso, a investigação ${ }^{1}$ desenvolvida vislumbrou a compreensão da atuação do Programa no âmbito do Instituto Federal de Educação, Ciência e Tecnologia do Triângulo Mineiro (IFTM) e os respectivos desdobramentos na formação inicial dos estudantes bolsistas do curso de Licenciatura em Química do Campus Uberaba, enquanto sujeitos presentes na realidade educacional das escolas públicas em que ocorrem as atividades, na tentativa de conciliar e relacionar os conhecimentos obtidos na práxis educativa.

Neste sentido, o trabalho teve como objetivo geral investigar a influência das atividades desenvolvidas pelo Programa Institucional de Bolsa de Iniciação à Docência na formação inicial dos estudantes bolsistas do curso de Licenciatura em Química do Instituto Federal de Educação, Ciência e Tecnologia do Triângulo Mineiro (IFTM) / Campus Uberaba, atuantes entre os anos de 2011 e 2013.

Por outro lado, os objetivos específicos desenvolvidos foram: descrever e apontar o perfil educacional dos estudantes do curso de Licenciatura em Química do Campus Uberaba, assim como as motivações da participação dos estudantes bolsistas no Pibid; explicitar e relatar as expectativas dos estudantes bolsistas acerca da carreira docente em relação às atividades desenvolvidas nas escolas conveniadas da rede pública de ensino; demonstrar e discutir os aspectos da influência do Pibid sobre os bolsistas integrantes frente à atuação docente e suas implicações.

Como desdobramentos, o presente relato investigativo buscou contribuir para a sistematização de reflexões sobre a atuação do Programa Institucional de Bolsa de Iniciação à Docência/IFTM e o apontamento das influências mais significativas na formação inicial de licenciandos de Química atuantes na realidade educativa do município de Uberaba - MG, destacadamente nas escolas da rede pública de ensino, assim como na formação continuada dos professores coordenadores de área do IFTM e dos professores supervisores atuantes na Educação Básica.

A relevância da abordagem do presente objeto de estudo se justifica pela natureza dos cursos de licenciatura das instituições de ensino superior no Brasil, especialmente os Institutos Federais de Educação, Ciência e Tecnologia (IFs).

Consoante a Lei Federal no 11.892, de 29 de dezembro de 2008 (Seção III, Art. 70), que institui a Rede Federal de Educação Profissional, Científica e Tecnológica, cria os Institutos Federais de Educação, Ciência e Tecnologia, e dá outras providências, um dos objetivos dos IFs consiste em: “VI - ministrar em nível de educação superior: [...] b) cursos de licenciatura, bem como programas especiais de formação pedagógica, com vistas na formação de professores para a educação básica, sobretudo nas áreas de ciências e matemática, e para a educação profissional; [...]".

\subsection{O Pibid no IFTM}

O Programa Institucional de Bolsa de Iniciação à Docência do Instituto Federal de Educação, Ciência e Tecnologia do Triângulo Mineiro (Pibid - IFTM) iniciou suas atividades em 2011, por meio do projeto institucional aprovado pelo Edital Capes no 01/2011, com subprojetos na área de

\footnotetext{
${ }^{1} \mathrm{O}$ presente artigo consiste em produto do projeto de iniciação científica desenvolvido no âmbito do Programa Voluntário de Iniciação Científica e Tecnológica (PIVIC) do IFTM e cadastrado na 1a chamada (02 a 13 de setembro de 2013) do Edital IFTM / PROPI no 06/2013: "Influências do Programa Institucional de Bolsa de Iniciação à Docência (PIBID) na formação de estudantes de licenciatura em Química do IFTM - Câmpus Uberaba (2011-2013)". O mesmo foi renovado durante a 2aㅡ chamada (06 a 24 de outubro de 2014) do Edital IFTM / PROPI no 08/2014.
} 
Química, Ciências Biológicas e Ciências Sociais (Campus Uberaba) e Computação (Campus Uberlândia Centro).

Esses subprojetos, sob a responsabilidade de seus respectivos coordenadores de área, foram executados em escolas da rede pública dos municípios de Uberaba - MG e Uberlândia - MG, congregando supervisores (professores da rede pública estadual selecionados por editais) e estudantes dos cursos de Licenciatura, com o acompanhamento da Pró-Reitoria de Ensino (PROEN) do Instituto Federal de Educação, Ciência e Tecnologia do Triângulo Mineiro - IFTM. Em 2012, foram iniciadas as atividades do segundo grupo Pibid - IFTM, aumentando o número de supervisores e de estudantes bolsistas.

Em dezembro de 2013, segundo o Relatório de geração de pagamento de bolsas disponível no sítio do Pibid (Capes) ${ }^{2}$, o Pibid do Instituto Federal de Educação, Ciência e Tecnologia do Triângulo Mineiro (IFTM) mantinha 21 professores supervisores atuantes nas escolas da rede pública dos municípios de Uberaba - MG e de Uberlândia - MG, além de 136 estudantes bolsistas dos cursos de Licenciatura, distribuídos em 4 subprojetos (ver Tabela 1: Números de estudantes bolsistas dos cursos de Licenciatura (Pibid/IFTM - campi Uberaba e Uberlândia Centro) - ref.: 12/2013):

Tabela 1: Números de estudantes bolsistas dos cursos de Licenciatura

(Pibid/IFTM - campi Uberaba e Uberlândia Centro) - ref.: 12/2013.

\begin{tabular}{c|c}
\hline Subprojeto / Campus & $\begin{array}{c}\text { Número de estudantes } \\
\text { bolsistas }\end{array}$ \\
\hline Ciências Biológicas (Campus Uberaba) & 40 \\
\hline Ciências Sociais (Campus Uberaba) & 37 \\
\hline Computação (Campus Uberlândia Centro) & 21 \\
\hline Química (Campus Uberaba) & 38 \\
\hline TOTAL & 136
\end{tabular}

Fonte: Baseado no Relatório de geração de pagamento de bolsas (12/2013) - Pibid/Capes.

Parte destas instituições aderiu ao Programa Institucional de Bolsas de Iniciação à Docência (Pibid /Capes), voltado para os estudantes de cursos de licenciaturas, a fim de consolidar a oferta da Educação Básica em nosso país, além de motivar os estudantes participantes, tornando as práticas de formação pedagógica mais participativas e integradas às necessidades educativas da sociedade em um contexto geral.

Com a inserção no referido programa, a expectativa é que haja condições mais propícias para a formação inicial dos licenciandos participantes e que prevaleça o desejo pela atuação docente, cada vez mais engajada socialmente.

Segundo Gatti et al (2014), os cursos de licenciatura não vinham oferecendo os conhecimentos e as habilidades necessários para o enfrentamento dos desafios educacionais, envolvendo práticas educacionais e atividades estimulantes. Por sua vez, o Pibid incentiva o magistério e o estudante do curso de licenciatura, propiciando ao participante um primeiro contato com o ambiente escolar, enquanto sujeito em formação para a docência.

\footnotetext{
${ }^{2}$ Disponível em: <http://www.capes.gov.br/images/stories/download/bolsas/30122014-Relatorio-de-bolsas-pibid .pdf> Acesso: 19 mar.2016.
} 
O contato dos licenciandos bolsistas com as escolas da rede pública de Educação Básica ocorre na observação das atividades pedagógicas desenvolvidas cotidianamente e também no planejamento e na execução de ações que deverão contribuir significativamente para o ensino e a aprendizagem.

O estudante bolsista do Pibid acompanha e auxilia no processo de ensino e de aprendizagem, juntamente com o professor supervisor. É importante que o pibidiano observe as mudanças ocorridas em toda a trajetória de sua participação no programa, promovendo sua avaliação continuamente, vislumbrando sua trajetória formativa como futuro docente.

\title{
2 REVISÃO BIBLIOGRÁFICA
}

Desde o início do Programa Institucional de bolsa de Iniciação à Docência - Pibid já vem sendo observada e investigada a influência exercida sobre seus participantes, sendo alvo de pesquisas, trabalhos e eventos de naturezas diversas, promovendo a explanação dos fundamentos teóricos da carreira docente considerados contemporaneamente e o debate em torno dos possíveis desdobramentos deste destacado e abrangente Programa na formação inicial de estudantes bolsistas, tanto quanto sua influência na cultura escolar da rede pública de ensino.

\begin{abstract}
O Programa Institucional de Bolsa de Iniciação à Docência (PIBID) vem se consolidando como uma das mais importantes iniciativas do país no que diz respeito à formação inicial de professores, surgindo como uma nova proposta de incentivo e valorização do magistério e possibilitando aos acadêmicos dos cursos de licenciatura a atuação em experiências metodológicas inovadoras ao longo de sua graduação. (BRAIBANTE e WOLLMANN, 2012, p. 167).
\end{abstract}

Para Braibante e Wollmann (2012), a Educação Básica deve ser refletida sobre a formação do professor, sendo hoje um grande desafio formar profissionais capacitados para atuarem no cenário escolar. Por isso, o programa tem um potencial muito significativo, pois proporciona aos participantes bolsistas a oportunidade de confrontar as explanações teóricas empreendidas em sala de aula do curso de Licenciatura com a realidade educativa presente nas escolas da rede pública de ensino, para que consigam exercer a formação acadêmica em preparação para o exercício da docência.

O trabalho de Garutti (2010), por exemplo, buscou analisar os dados oriundos de um levantamento sobre o cumprimento ou não dos objetivos preconizados pelo Programa Institucional de Bolsa de Iniciação à Docência (Pibid) no âmbito da Universidade Federal do Mato Grosso do Sul (UFMS), como possibilidade de avaliação dos resultados da atuação dos estudantes bolsistas do Pibid. Procurou abordar a opinião do futuro docente, atuando como participante do Pibid, ao

[...] investigar como o estudante se sente com relação a experiências [vividas nas escolas públicas], qual o papel que julga que elas têm em sua formação. Que importância ele atribui a esse quesito, se julga as impressões que teve através dessas interações estimulantes ou não, se essas experiências influenciam ou influenciaram na escolha da carreira e se o fizeram mudar de idéia em algum momento. (GARUTTI, 2010, p. 5) 
As relações estabelecidas entre a instituição de ensino superior e escolas públicas de Educação Básica são cruciais para a formação do futuro docente ao proporcionar elementos e cenários de observação e intervenção diretamente no dia a dia do processo de ensino e de aprendizagem na Educação Básica. Para Garutti (2010, p. 5), "[...] as escolas públicas conveniadas ao programa servem de laboratório para as ações dos acadêmicos pibidianos". Os estudantes bolsistas são inseridos gradativamente no cenário escolar, familiarizando-se com o futuro ambiente de trabalho, onde possam identificar certos desafios na educação pública e tentar propor uma solução, como afirma Braibante e Wollmann (2012, p. 172): "[...] desafios com possibilidades de serem vencidos".

Dentre as diversas produções já realizadas a respeito do Pibid e suas influências na formação inicial e continuada de professores no espaço escolar brasileiro, destaca-se o estudo avaliativo externo empreendido e publicado em 2014 pela Fundação Carlos Chagas (FCC) ${ }^{3}$, a pedido da Capes, sob a responsabilidade das pesquisadoras especialistas em formação de professores: Bernardete Angelina Gatti e Marli Eliza Dalmazo Afonso de André (2014).

As pesquisadoras desenvolveram uma metodologia que alcançou a amostra de $\mathbf{3 8 . 0 0 0}$ bolsistas, dentre os 45.000 participantes do Programa, por meio de questionário investigativo sobre aspectos abordados como: fundamentos teóricos, desenvolvimento, gestão, perspectivas e desdobramentos na prática cotidiana das instituições envolvidas e na formação inicial e continuada dos bolsistas. Sendo assim, este estudo serviu também como fundamentação teórica da investigação aqui realizada, demonstrando os principais aspectos considerados em torno da formação docente (GATTI ET AL, 2014).

Logo, a importância de um programa voltado para a formação de professores dessa natureza é caracterizada e analisada por Gatti et al (2014), que perceberam um número razoável de pesquisas sobre o programa Pibid, geralmente com foco local e caráter qualitativo. Todavia, considerados em seu conjunto, podem oferecer uma ampla visão sobre os efeitos do Pibid na formação inicial de docentes para a Educação Básica, da mesma maneira que para as próprias IES e escolas públicas, com oportunidades de estudos, pesquisa e extensão.

\section{METODOLOGIA}

As atividades investigativas foram importantes para o desenvolvimento da pesquisa, abordando questões qualitativas e quantitativas intrínsecas ao Programa Institucional de Bolsa de Iniciação à Docência (Pibid), a partir da formulação, da execução e da avaliação das atividades desenvolvidas no espaço formativo e educativo.

Para uma abordagem efetiva destas questões, objetos de investigação relacionados à influência do Pibid na formação dos estudantes bolsistas de Licenciatura em Química do Campus Uberaba do Instituto Federal de Educação, Ciência e Tecnologia do Triângulo Mineiro (entre 2011 - início das atividades do Pibid no IFTM e 2013 - término da vigência do Edital), houve a necessidade de uma pesquisa bibliográfica com o intuito de compreender a produção já realizada

\footnotetext{
${ }^{3}$ Disponível em: <http://www.capes.gov.br/images/stories/download/bolsas/24112014-pibid-arquivoAnexado.pdf> Acesso: 19 mar.2016.
} 
sobre o assunto e o entendimento das facetas relacionadas à formação inicial e continuada de professores no Brasil, em geral, e a atuação do Pibid, de modo particular.

Para a realização desta investigação e o desenvolvimento dos objetivos já explicitados anteriormente, houve o desenvolvimento de pesquisa bibliográfica e documental - Gil (2002); Marconi e Lakatos (2003), com abordagem essencialmente qualitativa - Strauss e Corbin (2008); Lüdke e André (2014), pois a quantidade e a qualidade são dimensões indissociáveis e mesmo dados coletados estatisticamente precisam ser abordados qualitativamente. Sendo assim,

As implicações desses pontos para a relação de procedimentos qualitativos e quantitativos são diretas. A não ser que seja indevidamente restrita, rotinizada ou ideologicamente blindada, pode-se fazer pesquisa útil com várias combinações de procedimentos qualitativos e quantitativos. Isso é válido para todas as fases da pesquisa, não importa se os pesquisadores estão coletando dados, formulando hipóteses, tentando verificá-las ou dando exemplos ao redigir publicações. Indo ao centro da questão, nosso conselho [...] é pensar em termos de interação entre métodos qualitativos e quantitativos. (STRAUSS e CORBIN, 2008, p. 42, grifos dos autores)

Para a coleta de dados e evidências empíricas, elaborou-se um questionário com perguntas objetivas e discursivas sobre o programa investigado, a partir dos aspectos previstos nos objetivos específicos desta investigação, explicitados anteriormente. Por meio do questionário, foram abordadas a identificação pessoal / caracterização do perfil dos estudantes bolsistas do curso de Licenciatura em Química, assim como três temáticas principais na forma de 3 blocos respectivos (com 4 questões objetivas e 1 discursiva por bloco): Bloco I - "motivos e expectativas dos bolsistas em relação à carreira docente"; Bloco II - "atividades desenvolvidas pelo Pibid / IFTM (subprojeto - Química)"; Bloco III - "avaliação das influências do Pibid em relação à carreira docente".

A validação do questionário foi realizada no sentido de verificar se todos os aspectos prescritos e os objetivos previstos pelo Pibid estavam também contemplados nas temáticas abordadas, embasadas nos elementos teóricos levantados por meio de pesquisa bibliográfica e documental prévia. Além do mais, foram promovidos pré-testes e os devidos ajustes necessários, garantindo a facilitação do entendimento por parte dos sujeitos.

Além do mais, o projeto de pesquisa e os instrumentos correspondentes (questionário proposto; Termo de Consentimento Livre e Esclarecido - TCLE) foram devidamente cadastrados e protocolados na Plataforma Brasil de modo a obter a aprovação pelo Comitê de Ética em Pesquisa - CEP com seres humanos. Após a realização de ajustes indicados, o projeto de pesquisa foi aprovado por meio do CEP da Universidade Federal do Triângulo Mineiro - UFTM, sob o Parecer Consubstanciado de número: 673.877 (04/06/2014).

Após aprovados os instrumentos de pesquisa pelo CEP / UFTM, o questionário foi disponibilizado via e-mail pessoal aos sujeitos da pesquisa por meio do Google Drive - ferramenta de questionário on-line do Google: estudantes bolsistas participantes do programa Pibid - IFTM, subprojeto de Química. Entre os anos de 2011 (início das atividades do Projeto institucional aprovado pelo Edital Capes no 01/2011) e 2013 (término da vigência do Edital Capes no 01/2011), por meio do levantamento e da análise dos relatórios de geração de pagamento de bolsas emitidos e disponibilizados pela Capes, foi constatado que um total de 40 estudantes bolsistas participou do subprojeto do curso de Licenciatura em Química. Antes de responderem ao questionário 
supracitado, todos os sujeitos envolvidos foram convidados para colaborarem com a investigação e estiveram cientes do teor da pesquisa, por meio da disponibilização do Termo de Consentimento Livre e Esclarecido - TCLE.

A disponibilização dos questionários foi realizada durante os meses de outubro e novembro de 2014, quando e-mails foram enviados aos 40 estudantes bolsistas participantes do Pibid/subprojeto de Química/IFTM, atuantes entre 2011 e 2013. No entanto, apesar dos esforços de conscientização e de divulgação, desses 40 participantes, apenas 15 dos sujeitos responderam ao questionário. Neste sentido, nas análises empreendidas, optamos por utilizar o formato fracionado, sempre indicando o número absoluto de respondentes (XX) em um total de 15 estudantes bolsistas respondentes: XX/15.

Por sua vez, deve ser ressaltado que os resultados do questionário foram publicados e o seu acesso permitido a todos os sujeitos, preservado o anonimato dos respondentes. Em abordagens informais, alguns dos sujeitos que não responderam ao questionário alegaram falta de tempo ou de interesse em participar da investigação.

Enfatiza-se que as opiniões expressas por meio das questões discursivas pelos estudantes bolsistas foram enumeradas (de 1 a 15) de acordo com a ordem disponibilizada pelo Google Drive e citadas ao longo da análise de dados como Bolsista do Pibid - BP $(1,2,3 \ldots 15)$ para melhor visualização e análise dos resultados.

A partir do levantamento dos dados quantitativos e qualitativos, oriundos dos questionários respondidos, houve a especificação de categorias de análise / indicadores, com a interpretação crítica dos resultados obtidos, tendo como pressuposto metodológico a análise de conteúdo, segundo as ideias de Bardin (2011): pré-análise; exploração do material; o tratamento dos resultados, a inferência e a interpretação.

Em outras palavras, diante de diferentes visões dos sujeitos participantes, a interpretação se torna essencial para dar sentido ao relato final da pesquisa realizada. A visão analítica, portanto crítica, é fundamental para transformar o resultado da investigação em mecanismos ou informações relevantes para a intervenção na realidade abordada.

\section{RESULTADOS E DISCUSSÕES}

\subsection{Apresentação e análise das respostas obtidas}

Como já informado anteriormente, o instrumento de coleta de dados foi dividido em duas partes: Parte 1. Identificação Pessoal e Parte 2. Questionário do Pibid. A Parte 2, por sua vez, foi fracionada em 3 blocos, a saber:

Bloco 1: Motivos e Expectativas dos Bolsistas em relação à Carreira Docente;

Bloco 2: Atividades desenvolvidas pelo Pibid / IFTM (subprojeto - Química) e;

Bloco 3: Avaliação das influências do Pibid em relação à Carreira Docente.

Cada um dos três blocos apresentou uma questão discursiva. Esses dados discursivos foram transcritos com a utilização de uma sigla (de acordo com a legenda abaixo) como identificação dos 
15 estudantes bolsistas do Pibid respondentes, com o intuito de preservar a identidade pessoal dos sujeitos da pesquisa:

Tabela 4.2 Caracterização dos estudantes bolsistas da Licenciatura em Química do IFTM / Campus Uberaba participantes do Pibid

\begin{tabular}{|c|c|c|c|}
\hline BP: Bolsista do Pibid & I: Idade & S: Sexo & P: Profissão \\
\hline$(1,2 \ldots 15)$ & $(18,19 \ldots 50)$ & $\begin{array}{l}\text { f: feminino } \\
\text { m: masculino }\end{array}$ & $\begin{array}{l}\text { es: estudante } \\
\text { p: professor } \\
\text { em: empresário } \\
\text { au: auxiliar administrativo } \\
\text { m: motorista } \\
\text { ag: agente de segurança }\end{array}$ \\
\hline
\end{tabular}

Essa vertente de questões teve a finalidade de descrever o perfil educacional dos estudantes bolsistas participantes do Pibid, subprojeto de Química, do IFTM / Campus Uberaba. As análises são descritas a seguir: a maioria dos licenciados bolsistas que respondeu ao questionário eram mulheres (8/15). A cidade com o maior número de residentes é Uberaba - MG (6/15), seguida por outras cidades vizinhas como Igarapava - SP, Uberlândia - MG e Conquista MG.

Aproximadamente 4/15 dos respondentes dedicam-se exclusivamente aos estudos, caracterizando a profissão de estudante, outra parcela (3/15) já atua como professor na Educação Básica, e o restante atua em outras profissões, como: agente de segurança, auxiliar administrativo, empresário e motorista.

É possível perceber que a maioria dos participantes do programa possui um tempo de dedicação maior à graduação e aos projetos do Pibid. Possuindo outra ocupação, a efetivação das atividades nas escolas torna-se menos concreta, uma vez que no Edital de seleção de alunos bolsistas (2011) (tópico 5.d) há a exigência da disponibilidade de tempo para participar efetivamente do projeto.

Todos os entrevistados participaram do programa como bolsista. 11/15 dos licenciandos afirmaram ter realizado o ensino médio totalmente em escola pública, 3/15 declararam ter feito parcialmente em escola pública e privada e, 1/15, totalmente em escola do setor privado. Em relação ao curso, 11/15 dos licenciandos consideram o curso de Licenciatura em Química do IFTM em nível médio de dificuldade, outros $3 / 15$ consideram-no como um curso fácil.

\subsection{Influências das atividades desenvolvidas no Pibid IFTM}

Para a análise efetiva dos questionários e melhor interpretação dos dados, os resultados obtidos foram organizados e citados acompanhando os diferentes blocos de eixos temáticos, compostos, cada um deles, por quatro questões de múltipla escolha e uma questão discursiva. $A$ análise das respostas discursivas obtidas pelos questionários foi organizada de acordo com os tópicos com maior ênfase levantados pelos licenciandos bolsistas em suas colocações. Durante a descrição e a apresentação dos dados dissertativos, alguns depoimentos foram selecionados para ilustrar os tópicos da análise, sem nenhuma modificação ou intervenção em relação à resposta dos licenciandos. 


\subsection{BLOCO I: MOTIVOS E EXPECTATIVAS DOS BOLSISTAS EM RELAÇÃO À CARREIRA DOCENTE}

O primeiro bloco temático objetivou explicitar as expectativas dos estudantes bolsistas de Licenciatura em Química sobre sua carreira docente. A escolha do curso de Licenciatura em Química ocorreu principalmente devido à afinidade com a disciplina de Química em 8/15 dos entrevistados. Uma parcela significativa, 4/15, afirmou desejar ser professor, e por essa razão ter escolhido um curso de licenciatura. Outro estudante escolheu o curso por falta de opções dentre os cursos do IFTM, ofertados no noturno. 2/15 não opinaram frente à questão. Este ponto trouxe dois dados importantes: se o licenciando tem a afinidade pela disciplina, ele deseja seguir a carreira docente, pois são duas características complementares e essenciais em um futuro docente de Química.

Atualmente, sabe-se da importância da formação continuada do professor, como afirma Felício (2014), em decorrência principalmente das responsabilidades e dos desafios crescentes que a sociedade contemporânea atribui ao sistema educacional e aos professores, evidenciando também diversas mudanças sociais nas propostas educacionais e na atuação dos professores. Esse aspecto foi evidente após a conclusão do curso, sendo que 6/15 dos participantes da pesquisa desejam fazer pós-graduação (especialização, mestrado e doutorado) e 3/15 desejam atuar em uma profissão relacionada à Química, diferente da carreira docente. Os outros respondentes dividiram-se em: 2/15 querem atuar como professor da Educação Básica, 2/15 continuar no atual trabalho e 2/15 ainda têm indecisão quanto ao futuro profissional. Essa resposta pode estar relacionada a uma tendência: licenciandos que desejam continuar sua formação acadêmica seguirão a carreira docente, seja de nível básico ou superior, essa característica pode ser confirmada na próxima questão.

O principal objetivo de um curso de Licenciatura, segundo a LDB № 9.394, de 20 de dezembro de $1996^{4}$, art. 62, consiste na formação de docentes para atuar na Educação Básica. E para cumprir esse objetivo, o Pibid busca incentivar a formação de professores, especialmente para o Ensino Médio. Apesar dos mais recentes avanços em termos de aumento do número de vagas e do número de matrículas em cursos de licenciatura em todo o país, essa característica fundamenta-se, principalmente, na evidente escassez de professores com titulação adequada atuantes no Ensino Médio. Em 2007, um relatório produzido pela Comissão Especial instituída para estudar medidas que visem a superar o déficit docente no Ensino Médio (BRASIL, 2007), junto à Câmara da Educação Básica / Conselho Nacional de Educação, já apontava a necessidade de cerca de 235 mil professores para o Ensino Médio no país, particularmente nas disciplinas de Física, Química, Matemática e Biologia.

Diante desse déficit de profissionais, o curso de licenciatura do IFTM inspira 9/15 dos licenciandos bolsistas a serem professores, outros 3/15 são inspirados a continuarem nos estudos, o que não descarta a possibilidade da carreira docente, 2/15 aspiram outro curso superior e 1/15 deseja seguir uma profissão diferente do magistério. Tal dado quantitativo induz o cumprimento do objetivo principal do curso e do Pibid.

${ }^{4}$ Para a leitura do texto da LDB no 9.394, de 20 de dezembro de 1996, na íntegra: <http://www.planalto.gov.br/ccivil_03/leis/19394.htm> Acesso em: 19 mar.2016 
Em relação ao curso de Licenciatura em Química do IFTM, 9/15 dos licenciandos sentem-se motivados a seguir a carreira docente, enquanto apenas $3 / 15$ sentem-se desmotivados. Uma diferença entre a quantidade de licenciandos motivados e desmotivados diante deste tópico é bastante significativa no cenário social atual, principalmente devido aos empecilhos apontados, como: baixa remuneração, precárias condições de trabalho e o pouco incentivo na formação de professores. 2/15 desejam seguir a carreira de químico, atuando em laboratórios e indústrias. $\mathrm{E}$ $1 / 15$ sente-se indiferente quanto à carreira docente.

Questão Discursiva: Comente sobre as suas expectativas em relação à carreira docente.

\subsubsection{SENTIR-SE PREPARADO PARA SER PROFESSOR}

O curso de licenciatura visa a formação de professores de qualidade para atuarem na Educação Básica, que saibam agir diante de uma sala de aula, com experiência suficiente para contribuir para a educação efetiva do cidadão. Esse objetivo é muito amplo e exigiria uma formação inicial de maior tempo e dedicação, pois é necessária uma constante construção pessoal diante das experiências adquiridas, para ser um professor de qualidade.

O Pibid permitiu aos estudantes bolsistas a vivência na realidade escolar em uma perspectiva diferente do estágio supervisionado obrigatório.

Em relação à carreira de professor me sinto preparado pelo IFTM para dar aulas, pretendo continuar os estudos o curso me proporcionou grande conhecimento em relação à Química e a outras matérias $\left(\mathrm{BP}_{14} \mathrm{l}_{32} \mathrm{~S}_{\mathrm{m}} \mathrm{P}_{\mathrm{m}}\right)$.

\subsubsection{FORMAÇÃO CONTINUADA}

O Pibid, segundo Gatti et al (2014), é formação inicial aos graduandos e formação continuada aos professores das escolas públicas e da IES. Embora exista a oferta deste programa aos licenciandos, o futuro professor precisa estar em constante atualização, com cursos de pósgraduação ou aperfeiçoamento e essa realidade não é ofertada pelo IFTM, até então.

Após um ano de conclusão de curso não consegui nenhum emprego estável e o IFTM não oferece nenhuma pós-graduação que atenda a este curso $\left(\mathrm{BP}_{12} \mathrm{I}_{22} \mathrm{~S}_{\mathrm{f}} \mathrm{P}_{\mathrm{p}}\right)$.

O curso de Licenciatura em Química tem proporcionado crescimento não apenas intelectual, mas também voltado para outras áreas da formação humana, como a postura crítica, a organização, a consciência política, permitindo aos estudantes o aprimoramento de suas capacidades e habilidades intelectuais, afetivas e sociais.

[...] todas as oportunidades do instituto me fizeram conhecer minhas capacidades, e hoje, pretendo fazer mestrado, para ser uma profissional de qualidade, na área de Química e continuar na área da docência $\left(\mathrm{BP}_{1} \mathrm{I}_{21} \mathrm{~S}_{\mathrm{f}} \mathrm{P}_{\mathrm{es}}\right)$.

\subsubsection{EXPECTATIVAS, PERSPECTIVAS E EXPERIÊNCIAS}

Alguns bolsistas já tinham o desejo pela carreira docente antes do curso, alguns foram repensando suas opções durante o curso, outros ainda não desejam ser professores, mas afirmam ter aprendido muito com as experiências. A oferta de diferentes atividades pelo IFTM, envolvendo 
estágio, monitoria, extensão, pesquisa, participação em eventos de diversas modalidades (palestras, seminários, congressos, fóruns, mesas redondas, colóquios, etc.) e o Pibid, fortalece o crescimento pessoal e social do estudante.

[...] Tenho boas expectativas em relação à carreira docente, pois já tive contato direto com sala de aula e alunos, e não encontrei dificuldades em ministrar aulas $[\ldots]\left(\mathrm{BP}_{3} \mathrm{I}_{43} \mathrm{~S}_{\mathrm{m}} \mathrm{P}_{\mathrm{p}}\right)$.

[...] O curso me propiciou muitas experiências boas, o modelo de estágio a ser seguido propiciou uma real experiência e análise sobre a profissão e o Pibid me permitiu desenvolver atividades dinâmicas [...] ( $\left.\mathrm{BP}_{12} \mathrm{I}_{22} \mathrm{~S}_{\mathrm{f}} \mathrm{P}_{\mathrm{p}}\right)$.

[...] IFTM me proporcionou uma nova expectativa para que no futuro bem próximo possa ser transmitido tudo o que os verdadeiros mestres me ensinaram. $\left(\mathrm{BP}_{13} \mathrm{I}_{25} \mathrm{~S}_{\mathrm{f}} \mathrm{P}_{\mathrm{es}}\right)$.

Percebe-se, também, novas perspectivas em relação à formação cidadã e, consequentemente, na relação com o mundo, a natureza e a sociedade, tendo maior conscientização de seu papel diante da realidade, no exercício de seus direitos e deveres.

O curso me proporcionou uma nova expectativa de como ver a vida o mundo e as pessoas, sabendo distinguir conceitos é éticas perante as pessoas [...] $\left(\mathrm{BP}_{13} \mathrm{I}_{25} \mathrm{~S}_{\mathrm{f}} \mathrm{P}_{\mathrm{es}}\right)$.

\subsubsection{INCENTIVO E MOTIVAÇÃO}

O incentivo externo aos futuros professores é de grande importância para a formação acadêmica de qualidade, além da motivação em seguir no curso de licenciatura, contribuindo para a busca de melhorias para a situação, na qual possam contribuir eficazmente para a formação de cidadãos críticos.

[...] Mesmo que seja difícil ser professor no Brasil - devido às condições de trabalho ofertado - é imprescindível que busquemos por melhoras nesse quadro, e isso cabe aos cidadãos conscientes, com atitude e críticos, uma característica de um bom professor $\left(\mathrm{BP}_{1} \mathrm{I}_{21} \mathrm{~S}_{\mathrm{f}} \mathrm{Pes}\right)$.

O IFTM e os programas ofertados, segundo os licenciandos, propiciam condições que incentivam e contribuem para a escolha da carreira, uma concepção que foi adquirida com o andamento das atividades do curso.

[...] O IFTM e seus servidores incentivam a carreira docente e oferecem recursos e oportunidades para ter uma experiência na área de atuação. Principalmente por meio do Pibid ( $\left(\mathrm{BP}_{11} \mathrm{I}_{22} \mathrm{~S}_{\mathrm{f}} \mathrm{P}_{\mathrm{es}}\right)$.

[...] O curso me proporcionou uma experiência nunca vivida, como motivação de ser um professor, algo novo, seminários, palestras e outros eventos relacionados à licenciatura $\left(\mathrm{BP}_{10} \mathrm{l}_{29} \mathrm{~S}_{\mathrm{m}} \mathrm{Pag}_{\mathrm{ag}}\right)$.

Com o curso, me sinto mais motivado a ser professor, já entrei no curso com esse ideal, agora pretendo realizá-lo $\left(\mathrm{BP}_{15} \mathrm{I}_{24} \mathrm{~S}_{\mathrm{m}} \mathrm{P}_{\mathrm{es}}\right)$. 


\subsubsection{BENEFÍCIOS AOS ESTUDANTES E BOLSISTAS}

Em todo o processo educacional, as atividades docentes conseguem atingir muitos grupos: a organização escolar, os professores, os estudantes, suas famílias e toda a sociedade. A preocupação em beneficiar o próximo, em sua profissão, deve ser uma prioridade.

Espero que (ser professor) seja algo prazeroso, onde meus alunos entendam o conteúdo que irei lecionar, que seja algo que irá beneficiar os meus alunos como pessoa e como furtos ingressantes em um curso superior $\left(\mathrm{BP}_{6} \mathrm{I}_{26} \mathrm{~S}_{\mathrm{m}} \mathrm{P}_{\mathrm{es}}\right)$.

\subsection{BLOCO II - ATIVIDADES DESENVOLVIDAS PELO PIBID / IFTM (SUBPROJETO - QUÍMICA):}

O segundo bloco temático objetivou apontar os motivos da participação do estudante bolsista no programa, relatar as atividades realizadas nas escolas conveniadas ao Pibid / IFTM e como ocorre a interação entre os estudantes bolsistas e as escolas públicas. Diante das respostas obtidas, o principal motivo para os licenciandos participarem do Pibid foi devido à melhoria em sua formação docente, para $6 / 15$ dos respondentes. Outros $5 / 15$ foram motivados pelo recebimento da bolsa, custeada pela Capes, o que colabora para manter, financeiramente, o estudante no curso e permite uma dedicação de um tempo maior às atividades na escola. 1/15 afirmou participar do Pibid para obter melhor desempenho no curso. E 3/15 não souberam opinar.

A questão da disponibilidade de tempo consiste em aspecto considerável e relevante para o desenvolvimento das atividades do Pibid. Por exemplo, segundo a Portaria CAPES no 096, de 18 de julho de 2013, Art. 36,

[...] para concessão de bolsa de iniciação à docência, o estudante deverá atender aos seguintes requisitos: $\S 1$ o 0 estudante de licenciatura que possua vínculo empregatício poderá ser bolsista Pibid, desde que: I - não possua relação de trabalho com a IES participante do Pibid ou com a escola onde desenvolve as atividades do subprojeto; II - possua disponibilidade de 32 (trinta e duas) horas mensais para dedicação às atividades do projeto (BRASIL, 2013).

As atividades do Pibid na escola pública são feitas semanalmente por 12/15 dos estudantes bolsistas em uma média de 8 horas de dedicação. Apenas $2 / 15$ dos licenciandos não seguem periodicidade e 1/15 frequenta a escola uma vez por mês. A dedicação às atividades deve ser frequente, mesmo que à distância ou indiretamente. A participação semanal na escola permite o conhecimento do ambiente e da sala de aula, criando vínculos com os estudantes e possibilita a organização de atividades destinadas a uma turma em especial, com características definidas e analisadas pelo licenciando. As principais atividades desenvolvidas na escola foram monitoria e acompanhamento das atividades cotidianas de ensino e aprendizagem, elaboração de apostilas, participação em feiras de conhecimentos e de atividades extracurriculares.

As atividades desenvolvidas no Pibid permitiram aos licenciandos, principalmente, a possibilidade de aprimorar o desejo pela carreira docente, devido à aproximação com o ambiente escolar. Sendo assim,

A comparação das atividades realizadas no âmbito do Programa com os estágios curriculares parece inevitável. Notam-se dois tipos de depoimentos: o primeiro, e mais numeroso, é o dos Licenciandos que consideram as aprendizagens no Pibid 
de longe melhores do que no estágio (permanência de mais tempo na escola, oportunidade de conhecer a escola toda e sua dinâmica, de planejar atividades, de experimentar a docência, de conhecer ou criar materiais didáticos, orientados e apoiados pelos Supervisores e Coordenador de Área), e os que avaliam que o Pibid prepara para melhor aproveitamento do estágio obrigatório. Há depoimentos que deixam claro quão restritas são as orientações no estágio, quando não ausentes, e o pouco tempo que permanecem na escola, sempre como observadores passivos (GATTI et al, 2014, p. 63).

Outra característica destacada foi a participação em eventos da área de Educação e Química, custeada pelo IFTM e pela Capes, com o objetivo de representar o programa e as atividades desenvolvidas na escola, disseminando aos estudantes bolsistas e pesquisadores aprendizagem frente a toda experiência vivida. Outros pontos apontados, em minoria, foram a complementação da renda familiar mensal, a contribuição para a melhoria da Educação Básica e o desestímulo pela carreira docente.

Questão Discursiva: Impressões sobre o trabalho desenvolvido pelo seu grupo do Pibid junto à escola e os reflexos na educação desses estudantes.

\subsubsection{PROFESSORES SUPERVISORES E COORDENADORES}

Diante da observação e da execução das atividades do Pibid nas escolas, os licenciandos bolsistas destacaram e enalteceram a dedicação dos professores supervisores e coordenadores de área.

Ao começar a frequentar o projeto, percebi que os professores sim nos passam muitas atividades para dentro da sala de aula, mas a disponibilidade deles em estar nos orientando, é pequena. Sendo assim, algumas coisas que gostaríamos de estar passando para os alunos, acaba sendo deixada de lado devido ao pouco tempo dos nossos coordenadores $\left(\mathrm{BP}_{9} \mathrm{I}_{22} \mathrm{~S}_{\mathrm{f}} \mathrm{P}_{\mathrm{au}}\right)$.

Este trabalho permitiu que o grupo de graduandos colaborasse com o professor orientador para a construção de uma metodologia de ensino de mais qualidade, serviu para desenvolver atividades que o professor não tem tempo de elaborar e também não conseguiria gestar sozinho nas turmas que são muito cheias $\left(B P_{12} \mathrm{I}_{22} \mathrm{~S}_{\mathrm{f}} \mathrm{P}_{\mathrm{p}}\right)$.

As mudanças periódicas nas escolas ocasionam a construção da personalidade docente do licenciando, já que analisa as posturas e as responsabilidades dos orientadores e supervisores diante do Pibid.

[...] com duas professoras sem visão ou interesse, que usavam qualquer coisa como desculpa para não trabalhar $\left(\mathrm{BP}_{2} \mathrm{I}_{26} \mathrm{~S}_{\mathrm{f}} \mathrm{P}_{\mathrm{em}}\right)$.

\subsubsection{CONTATO COM A SALA DE AULA}

Com as atividades do Pibid, os licenciandos bolsistas têm um maior contato direto com todo o ambiente escolar e oportunidades de perceber as características do cotidiano do processo de ensino e de aprendizagem. 
O trabalho perante o Pibid, faz com que ao grupo, seja capaz de desenvolver várias atividades, podendo contribuir com a construção dos conhecimentos dos estudantes que através desse intermédio Pibid, faz com que os estudantes tenha um contato direto, não realmente com o professor mais sim com estudantes de graduação, assim podendo eles terem um aprendizado com o grupo e grupo ter um aprendizado juntamente com os estudantes do ensino médio, proporcionando diretamente a interatividade com o que se busca o projeto. Portanto esse trabalho faz diferença não só nos estudante do ensino médio, como os bolsistas do Pibid ( $\left.\mathrm{BP}_{13} \mathrm{I}_{25} \mathrm{~S}_{\mathrm{f}} \mathrm{P}_{\mathrm{es}}\right)$.

\subsubsection{APRENDIZAGEM DOS ESTUDANTES}

A concretização do processo de ensino e de aprendizagem dos estudantes consiste em um reflexo da qualidade de atividades pedagógicas desenvolvidas em sala de aula e, para isso, os pibidianos complementam as aulas dos professores.

O trabalho que desenvolvemos no Pibid vai desde palestras e minicursos sobre assuntos relacionados à Química, até visitas no IFTM para apresentação dos cursos. Elaboramos jogos, atividades diferenciadas, atividades de conscientização, atividades práticas e tentamos melhorar a qualidade do ensino de Química nas escolas. Sempre que possível, aplicamos questionários para verificar se os alunos estão gostando das atividades e, sempre, as respostas são positivas, o que colabora para que possamos pensar em novas atividades melhores para atrair os alunos no universo da Química $\left(\mathrm{BP}_{1} \mathrm{I}_{21} \mathrm{~S}_{\mathrm{f}} \mathrm{P}_{\mathrm{es}}\right)$.

[...] este trabalho contribuiu muito para que os estudantes entendessem as diferentes formas de aprender Química, a real importância de se aprender a Química com atividades lúdicas e experimentação $\left(\mathrm{BP}_{12} \mathrm{I}_{22} \mathrm{~S}_{\mathrm{f}} \mathrm{P}_{\mathrm{p}}\right)$.

A interação entre os graduandos bolsistas e o professor supervisor contribui para a construção de uma metodologia de ensino de maior qualidade nas escolas públicas. Percebe-se a preocupação dos licenciandos na relação bilateral do ensino e na verificação das consequências do processo nos estudantes.

\subsubsection{LIBERDADE}

O desejo em alterar as concepções de ensino deve vir acompanhado por condições que possibilitem o desenvolvimento de projetos educacionais. A liberdade oferecida pela escola e pelo supervisor tem grande influência nos resultados esperados pelos bolsistas.

[...] A escola pública nos permite fazer todas as atividades, somos bastante livres para elaborar projetos e executá-los $\left(\mathrm{BP}_{1} \mathrm{I}_{21} \mathrm{~S}_{\mathrm{f}} \mathrm{P}_{\mathrm{es}}\right)$.

[...] nosso coordenador nos dá a livre espontaneidade de trabalhar com os alunos tanto em aprendizado em sala de aula como experimentos em laboratório $\left(\mathrm{BP}_{10} \mathrm{I}_{29} \mathrm{~S}_{\mathrm{m}} \mathrm{P}_{\mathrm{ag}}\right)$. 


\subsection{BLOCO III - AVALIAÇÃO DAS INFLUÊNCIAS DO PIBID EM RELAÇÃO À CARREIRA DOCENTE}

O terceiro e último bloco temático objetivou discutir os estímulos ocasionados pelo programa como estímulo para a docência. A participação no programa, o conhecimento da realidade escolar e a elaboração dos trabalhos a serem executados em sala de aula caracterizam as principais atividades desempenhadas pelos licenciandos e estas estimulam 9/15 dos estudantes bolsistas a serem professores e buscarem atuar no ensino de Química das escolas públicas. Outros $2 / 15$ sentem-se estimulados a serem professores, mas preferem atuar em outra profissão. 2/15 não se sentem estimulados, mas seguirão a carreira de docência em Química. Apenas 1/15 foi desestimulado quando da participação no Pibid e tentará outra área profissional. $1 / 15$ preferiu não opinar.

A melhoria da capacidade em conceber e desenvolver projetos de intervenção docente no processo de ensino e de aprendizagem foi a influência positiva mais percebida por 7/15 dos participantes do Pibid. 3/15 dos licenciandos afirmaram ter percebido que a atuação docente nas escolas públicas é fundamental para o desenvolvimento do país, do mesmo modo que 3/15 perceberam que aprimoraram diversas habilidades de investigação pedagógica, além de modelos de metodologias e técnicas de ensino e de aprendizagem. 1/15 bolsista conseguiu aprender a desenvolver atividades em grupo e aperfeiçoar habilidades de convivência e comunicação após participar do Pibid. 1/15 não opinou a este respeito.

Diante da participação no Pibid, segundo os bolsistas, o maior desafio encontrado foi relacionado aos problemas de infraestrutura predial, como falta de laboratórios e equipamentos adequados ao ensino de Química, para 7/15 dos respondentes. Outros 4/15 dos licenciandos bolsistas apontaram a ausência de condições relacionada à área pedagógica da escola, que impossibilitava a eficácia do desenvolvimento de atividades no processo de ensino e de aprendizagem. 3/15 dos bolsistas acreditam que o maior obstáculo é a desvalorização social do professor e a falta de programas políticos que apóiam a Educação Básica pública. 1/15 não apontou nenhuma das alternativas disponíveis.

Para 7/15 dos licenciandos, a iniciativa que mais interfere positivamente na formação dos professores atuantes na Educação Básica é a promoção de campanhas que buscam a valorização da carreira docente perante a sociedade. 3/15 afirmaram sobre a importância e a necessidade de maiores investimentos em programas governamentais de estímulo à licenciatura, como o Pibid. 1/15 apontou a necessidade da reformulação das propostas pedagógicas dos cursos, a fim de dinamizar as atividades de formação inicial de professores, fundamentada em disciplinas específicas voltadas à preparação de um futuro profissional da educação. 1/15 sentiu falta da produção de materiais pedagógicos educativos para auxiliarem no ensino de Química nas escolas onde atuam. 3/15 não apontaram nenhuma das alternativas apresentadas.

Questão Discursiva: Efeitos do Pibid em sua formação como futuro docente. 


\subsubsection{CONTATO COM ESTUDANTES}

Enquanto apenas estudantes, os licenciandos não possuem uma vivência no cenário escolar, enfrentando os obstáculos da sala de aula, pois ser professor implica em buscar os melhores meios para proporcionar uma aprendizagem significativa.

A aula mais dinâmica e prática que pode ser feita em sala, usando materiais alternativos. Como consequência o Pibid me ajuda a saber o professor que quero ser e o professor que não que não quero ser! Me ajuda a saber como lidar com os alunos, como usar uma didática que vá abranger a todos os discentes! $\left(\mathrm{BP}_{6} \mathrm{I}_{26} \mathrm{~S}_{\mathrm{m}} \mathrm{P}_{\mathrm{es}}\right)$.

O Pibid me proporcionou uma nova expectativa referente à licenciatura, me proporcionou contato direto com os estudantes [...] o Pibid proporcionou a mim, uma nova expectativa de vida referente aos meus desejos de continuar nessa profissão $\left(\mathrm{BP}_{13} \mathrm{l}_{25} \mathrm{~S}_{\mathrm{f}} \mathrm{P}_{\mathrm{es}}\right)$.

[...] uma visão ampla e direta dentro da área de atuação um contato direto com os alunos e uma renda extra para melhorar nos estudos $\left(\left.\mathrm{BP}_{14}\right|_{32} \mathrm{~S}_{\mathrm{m}} \mathrm{P}_{\mathrm{m}}\right)$.

\subsubsection{CRESCIMENTO E SEGURANÇA PESSOAL}

As vivências em sala de aula e as experiências proporcionadas pelo Pibid colaboraram para o crescimento dos bolsistas, em âmbitos diversos, tanto em crescimento intelectual, como afetivo e social.

Todas as experiências que tive na faculdade me levaram a escolher a profissão e me fizeram crescer como ser humano, pois aprendi a conviver em grupo (uma dificuldade que eu tinha), aprendi a pensar em maneiras alternativas de ensinar um determinado conteúdo, descobri o que eu mais gosto de fazer: ensinar o outro. Quando sabe-se aproveitar, o Pibid é uma iniciativa do governo que apenas colabora com a nossa formação docente e traz apenas benefícios para a formação cidadã $\left(B P_{1} I_{21} \mathrm{~S}_{\mathrm{f}} \mathrm{P}_{\mathrm{es}}\right)$.

O Pibid me deu segurança em exercer a carreira docente pois uma formação de Licenciaturas sem ocorrências de práticas antes do contato direto com os alunos leva-se uma insegurança para os iniciantes à docência $\left(\mathrm{BP}_{3} \mathrm{l}_{43} \mathrm{~S}_{\mathrm{m}} \mathrm{P}_{\mathrm{p}}\right)$.

\subsubsection{FORMAÇÃO ACADÊMICA}

O curso de licenciatura propicia condições favoráveis à formação docente, voltadas para a apreensão de elementos significativos para o processo de ensino e aprendizagem, resultante do conhecimento específico da área do conhecimento e das disciplinas pedagógicas.

[...] proporcionou-me segurança para as práticas docente para com os alunos $\left(\mathrm{BP}_{8} \mathrm{I}_{43} \mathrm{~S}_{\mathrm{m}} \mathrm{P}_{\mathrm{p}}\right)$.

[O Pibid] é de extrema importância, pois colocamos em prática o que aprendemos em matérias pedagógicas $\left(\mathrm{BP}_{11} \mathrm{I}_{22} \mathrm{~S}_{\mathrm{f}} \mathrm{P}_{\mathrm{es}}\right)$. 
Para um futuro professor, o Pibid atua como uma prévia da atuação escolar. Em outras palavras, o estudante não apenas simula as diversas situações em sala de aula da Licenciatura, mas também tem a oportunidade da vivência no cotidiano escolar.

[...] o Pibid veio de grande ajuda não só financeira mas sim de um estímulo à educação e aprendizagem como futuro professor, me auxiliando na minha formação, em sala de aula vivenciando isto tudo antes de me formar para mim esse projeto e de uma grande importância para nós que seremos futuros professores $\left(\mathrm{BP}_{10} \mathrm{I}_{29} \mathrm{~S}_{\mathrm{m}} \mathrm{P}_{\mathrm{ag}}\right)$.

\subsubsection{CONHECIMENTO DA REALIDADE ESCOLAR}

Enquanto estudantes voltados para o entendimento da Educação Básica, as análises e as percepções teóricas da escola são diferentes daquelas efetivamente práticas enquanto professor. A atuação como bolsista possibilita o conhecimento da realidade docente e escolar.

O Pibid me propiciou conhecimento da situação real em que se encontra as escolas públicas, a relação entre o professor e os alunos e as estruturas dos laboratórios de ensino. Como consequência disso, conheci o real mercado de trabalho que atuo e descobri que não pretendo continuar minha carreira nas escolas públicas por muito tempo. Pois as turmas são muito cheias, os alunos não respeitam o professor, o salário dos docentes é desvalorizado e o sistema governamental pressiona as escolas a passarem a maioria dos alunos e muitos se formam sem ser avaliados coerentemente $\left(\mathrm{BP}_{12} \mathrm{I}_{22} \mathrm{~S}_{\mathrm{f}} \mathrm{P}_{\mathrm{p}}\right)$.

\subsubsection{MOTIVAÇÃO E ESTÍMULO PARA A CARREIRA DOCENTE}

Os relatos dos licenciandos bolsistas do Pibid demonstraram, em sua maioria, a motivação em ser professor. As contribuições das atividades realizadas foram decisivas para a escolha em seguir ou não a carreira docente.

As atividades do Pibid, que realizamos desde o 2o período da faculdade me permitiram escolher a carreira docente como profissão, uma vez que participamos das atividades escolares e compreendemos detalhes deste cenário. [...] Quando sabe-se aproveitar, o Pibid é uma iniciativa do governo que apenas colabora com a nossa formação docente e traz apenas benefícios para a formação cidadã $\left(\mathrm{BP}_{1} \mathrm{I}_{21} \mathrm{~S}_{\mathrm{f}} \mathrm{P}_{\mathrm{es}}\right)$.

[...] o Pibid proporcionou a mim, uma nova expectativa de vida referente aos meus desejos de continuar nessa profissão $\left(\mathrm{BP}_{13} \mathrm{l}_{25} \mathrm{~S}_{\mathrm{f}} \mathrm{P}_{\mathrm{es}}\right)$.

O Pibid me deu segurança em exercer a carreira docente pois uma formação de Licenciaturas sem ocorrências de práticas antes do contato direto com os alunos leva-se uma insegurança para os iniciantes à docência $\left(\mathrm{BP}_{3} \mathrm{l}_{43} \mathrm{~S}_{\mathrm{m}} \mathrm{P}_{\mathrm{p}}\right)$.

\subsection{Análise geral dos resultados}

A partir da análise das respostas fornecidas pelos estudantes bolsistas do Pibid, de forma geral, verificamos o cumprimento dos objetivos principais do programa. O questionário disponibilizado aos estudantes bolsistas buscou verificar a influência das atividades do programa na formação do futuro docente. Embora tenha havido uma baixa participação relativa dos 
estudantes bolsistas na pesquisa (aproximadamente 30\% de respondentes), os resultados encontrados podem estar relacionados aos bolsistas mais empenhados no programa.

As questões objetivas informaram dados importantes sobre a escolha do curso de licenciatura, a afinidade pela docência e a motivação em ser professor de Química: 8/15 dos estudantes bolsistas participantes escolheram o curso pela afinidade e outra parcela menor desejava ser professor antes de ingressar na graduação. 6/15 dos estudantes bolsistas desejam fazer pós-graduação na área. Diante disso, embora inicialmente, os estudantes bolsistas escolheram o curso apenas pela área específica de Química. Posteriormente, foram motivados para a carreira docente, desejando atuar na área de educação, seja Básica ou Superior.

Nos discursos, observou-se que grande parte dos estudantes bolsistas construiu anseios positivos em relação à carreira docente, sendo estimulados a serem professores e a buscarem a qualidade do ensino de Química após a participação no programa. Uma minoria não pretende seguir a carreira inicialmente, mas afirmam que essa possibilidade pode vir a ser construída.

Os estudantes bolsistas do Pibid frequentam as escolas semanalmente, estando inseridos no cotidiano escolar e participando das atividades educacionais. Consequentemente, a maioria dos estudantes bolsistas procurou aprimorar seus desejos pela carreira docente.

O principal propósito do programa em estimular a carreira docente vem sendo concretizado com a maioria dos licenciandos bolsistas de Química e as conquistas pessoais e profissionais vem sendo efetivadas como: a capacidade de conceber e de desenvolver projetos de intervenção docente no processo de ensino e de aprendizagem, além de estarem acompanhando o desenvolvimento de habilidades na área de Educação, como a capacidade de expor ideias, falar em público e trabalhar em grupo.

Para os estudantes bolsistas, a maior dificuldade na atuação docente está relacionada aos problemas de infraestrutura das escolas públicas, como a falta de laboratórios e equipamentos adequados para o ensino de Química. Mas esse obstáculo pode ser superado com a formação continuada na área da Educação, além da atualização e consolidação dos conhecimentos específicos da área de Química, por exemplo.

Embora muitas atividades sejam realizadas nas escolas, ainda há a necessidade de analisar a qualidade de organização e aplicação dessas atividades, além do domínio dos conteúdos específicos, para que o estudante bolsista colabore significativamente com o ensino de Química, através da sua intervenção em sala de aula.

De maneira geral, os estudantes bolsistas acreditam que o Pibid contribui significativamente para a formação acadêmica e pessoal, como futuro docente. Mesmo que alguns não desejem seguir na carreira docente, as experiências adquiridas colaboraram com a concretização de opiniões pessoais sobre a educação pública brasileira, amadurecendo seus conceitos e ideologias diante dessa realidade, sejam elas positivas ou negativas.

O Pibid estimulou os estudantes bolsistas em seguir a carreira docente, mesmo aqueles que, inicialmente, escolheram o curso apenas pela afinidade pela Química. O principal motivo da participação no programa foi a busca pela melhoria na formação, acompanhado também pelo apoio financeiro proporcionado pelo recebimento da bolsa. As expectativas em relação à carreira docente nos discursos dos estudantes bolsistas são geralmente positivas, sendo que 9/15 desejam 
seguir a carreira docente e sentem-se preparados para assumir as atribuições inerentes, a partir das oportunidades oferecidas pela IES e pelas experiências adquiridas com o programa.

Para os estudantes do ensino médio, a relação com os licenciandos bolsistas insere-os em um cenário mais atual, conhecendo profundamente as oportunidades que eles virão a ter no futuro, como a escolha da carreira e a aprendizagem do conteúdo de Química. O estudante bolsista atua em duas realidades diferentes, simultaneamente: como estudante, necessita de realizar leituras de trabalhos realizados por especialistas nos assuntos a serem investigados, estudar os conteúdos de Química, participar de discussões construtivas com os professores da área de Educação, e; atua também como bolsista de iniciação à docência, que pode optar por aplicar as teorias didáticas aliadas às atualidades associadas ao conteúdo de Química. Nessa fase, onde o estudante bolsista atua em duas posições distintas, ele possui inúmeras possibilidades e artifícios de elevar a qualidade do ensino de Química nas escolas públicas onde atuam.

Baseado no conteúdo das questões objetivas e dos discursos dos estudantes bolsistas do Pibid observa-se o cumprimento dos objetivos anunciados do programa. Foi possível analisar a influência do Pibid na formação dos futuros professores, contribuindo para o primeiro contato com a escola pública, para a participação coletiva com professor da Educação Básica, propondo alternativas didáticas na sala de aula e contribuindo com o processo de ensino e de aprendizagem dos conteúdos de Química.

\subsection{Contribuição do Pibid para os estudantes bolsistas}

A importância do Pibid na formação dos estudantes bolsistas participantes foi verificada nas respostas dos questionários, aspectos positivos superam os negativos, em sua grande maioria. A visão favorecida do programa pelos estudantes bolsistas implica a necessidade de continuação e de investimentos na iniciativa, a partir do crescimento de valor dos cursos de licenciatura, qualificando a IES e seus docentes, contribuindo para a formação dos professores da Educação Básica e oportunizando condições de melhoria do processo de ensino e de aprendizagem.

A partir dos dados analisados, o Pibid IFTM - subprojeto de Química tem um grande impacto na formação inicial dos professores de Química, mesmo que ainda necessite de mudanças e adaptações.

A seguir, são apontados resumidamente os aspectos enunciados pelos participantes da pesquisa como principais contribuições do Pibid para a formação profissional, pessoal e acadêmica dos próprios estudantes bolsistas:

- Impressões sobre a profissão docente, já no início do curso: estudantes em sala de aula, o cotidiano da escola, propostas didáticas, obstáculos a enfrentar, metas a concretizar;

- Aplicação dos conteúdos vistos na graduação, em disciplinas específicas e pedagógicas, em metodologias de ensino na sala de aula do ensino médio;

- Conhecimento de habilidades pessoais relacionadas à elaboração de atividades didático-pedagógicas diante das dificuldades de aprendizagem encontradas em sala de aula, com estímulo à criatividade e à iniciativa em relação às propostas para o ensino de Química; 
- Aprimoramento da capacidade de realizar pesquisas no cenário escolar, analisando as consequências das metodologias utilizadas em relação à aprendizagem construída pelo aluno e os resultados diante de técnicas de ensino;

- Reconhecimento da importância das atividades desempenhadas em sala de aula para o crescimento dos estudantes;

- Contribuição para o desejo e o estímulo em atuar na carreira docente; e,

- Possibilidade de construção da experiência na atuação docente desde o início da graduação, colaborando com a qualidade na formação dos futuros professores.

\subsection{Desafios encontrados}

Os benefícios do Pibid para os estudantes bolsistas, para os supervisores da Educação Básica, para a escola pública e para a IES podem ser evidenciados nos conteúdos analisados pela pesquisa, mas algumas situações-problemas foram apontadas e serão de grande importância para colaborar com o melhor desenvolvimento do programa na instituição e no curso de Licenciatura em Química. Salienta-se que alguns problemas podem ser específicos em determinadas situações (necessidades pessoais, em escolas específicas, com supervisores específicos ou em outras situações) e não podem vistas de maneira global, mas, merecem destaque:

- Ausência da oferta de formação continuada na IES onde realizou a graduação, principalmente na área de Química;

- Dificuldade na comunicação entre a IES e a escola básica, com supervisores e coordenadores pouco empenhados e com pouco tempo disponível, devido ao acúmulo das outras atividades sob sua responsabilidade, excessiva burocracia e ausência de informações pertinentes ao favorecimento das atividades na escola;

- Grupos de atuação nas escolas com um número elevado de integrantes, quando os estudantes menos comprometidos encontram a possibilidade de camuflar-se dentre aqueles que atuam significativamente na escola, pois os trabalhos são avaliados pela IES a partir das atividades de todo o grupo e não individualmente;

- Dificuldades dos estudantes bolsistas em propor metodologias alternativas de ensino de Química, indicando a necessidade da oferta de cursos extracurriculares pela IES, que possam auxiliar no desenvolvimento de técnicas e metodologias no processo de ensino e de aprendizagem em Química;

- Não concretização de alguns dos objetivos traçados, sendo que os estudantes bolsistas propõem metodologias, mas o coordenador, por desconhecer as possibilidades, limita a abrangência do programa na sala de aula. Portanto, em alguns casos, há reduzida atuação na escola, pouco contribuindo para a construção do conhecimento de Química;

- Dificuldades em expor suas ideias por meio das questões discursivas, seja de forma escrita ou oral, com o mau uso da língua culta, indicando a necessidade em rever a aprendizagem da Língua Portuguesa dos estudantes bolsistas, futuros professores. 


\subsection{Algumas propostas}

Tendo em vista os resultados da aplicação do questionário, a observação do cotidiano das atividades executadas pelo Pibid, assim como outras informações oriundas pesquisa bibliográfica e documental, enfatizamos algumas iniciativas que poderão aprimorar e consolidar as ações do Programa, principalmente em relação aos estudantes bolsistas:

- O estímulo e o suporte à formação de Núcleos e Grupos de Pesquisa no âmbito da IES, sobretudo aqueles voltados para o estudo e o desenvolvimento de metodologias de ensino especificamente voltados para a área da Química, assim como o aperfeiçoamento de objetos de aprendizagem e técnicas didáticas;

- O empreendimento de parcerias com outros cursos da IES, destacadamente os cursos de bacharelado, técnicos integrados ao ensino médio e demais licenciaturas, com o intuito da troca de experiências e ações de formação continuada, assim como o estímulo ao ingresso de servidores voluntários no Pibid;

- O planejamento e a execução de ações voltadas para a formação continuada dos coordenadores de área, supervisores, bolsistas de iniciação à docência, enfim, iniciativas que tenham por referência a busca por saberes e práticas que auxiliem os sujeitos envolvidos no Pibid, por meio de: palestras; seminários; mesas redondas; colóquios; painéis; workshops; minicursos; reuniões ordinárias; etc.;

- A organização e o planejamento de atividades que resultem periódica e sistematicamente em produtos que possam ser divulgados e publicados em eventos da área da Educação e/ou da Química, do mesmo modo em revistas científicas, jornais de natureza acadêmica, livros: resumos; resumos expandidos; resenhas; pôsteres; trabalhos completos; comunicações orais; relatos de experiências; artigos; capítulos de livros; etc.;

- Apoio institucional no sentido de participar efetivamente de editais, sobretudo aqueles publicados por agências de fomento como, por exemplo: Fapemig; CNPq e Capes.

\section{CONCLUSÃO}

A partir da análise dos discursos dos estudantes bolsistas do Pibid/subprojeto de Química/ IFTM/Campus Uberaba, foi possível verificar e confirmar a importância da iniciativa do programa em relação à formação dos futuros professores de Química. As condições do Pibid possibilitam a criação de um processo de formação contínua para o crescimento profissional dos docentes, quando eles possam participar do processo de emancipação e desenvolvimento das pessoas como cidadãos (GATTI et al, 2014).

A influência significativa na formação pessoal e profissional dos estudantes bolsistas foi evidenciada pelos discursos e a motivação em seguir a carreira docente demonstra a eficácia do Programa em cumprir seu principal objetivo. Alguns aspectos necessitam de correções e aprimoramentos para que os desdobramentos no cenário educacional demonstrem a relativa influência do Pibid na melhoria futura da educação pública. 
Os desafios encontrados na experiência docente farão parte da rotina do futuro professor, sendo que cada um deles deverá buscar a melhor solução, para que assim consigam melhorar as condições de ensino das escolas públicas, acreditando na possibilidade de mudança no cenário educacional e que o Pibid seja peça fundamental dessa conquista.

Salientamos que iniciativas governamentais como o Pibid são fundamentais para a melhoria da educação pública. Todavia, são iniciativas que geralmente são pontuais e por si só não trazem efeitos duradouros e consolidados para a efetiva melhoria da educação básica. Esta precisa ser valorizada como Política Pública, assumida como compromisso do governo federal, estadual e municipal, independentemente das disputas partidárias. Os resultados da pesquisa mostram a eficácia do programa para que futuros estudantes possam se interessar pelo Pibid e por contribuir com a melhoria da formação acadêmica dos participantes.

Logo, de uma maneira geral, ressalta-se que os objetivos dos idealizadores e financiadores do programa estão sendo cumpridos. Os resultados, os projetos desenvolvidos, os incentivos da instituição de ensino superior (IES) e as atividades realizadas pelos pibidianos e seus efeitos na escola de Educação Básica são significativos, já que os investimentos da Capes para o desenvolvimento do programa são relevantes (cerca de 90 mil bolsistas, envolvendo estudantes da graduação, professores da Educação Básica e os coordenadores da IES). O Pibid pode colaborar significativamente para a redução da lacuna que existe entre os discursos pedagógicos e teóricos explanados nos cursos de licenciatura da IES e a prática efetiva nas escolas públicas.

\section{REFERÊNCIAS BIBLIOGRÁFICAS}

1. BARDIN, Laurence. Análise de conteúdo. Tradução de Luis Antero Reto; Augusto Pinheiro. São Paulo: Edições 70, 2011.

2. BRAIBANTE, Mara Elisa Fortes; WOLLMANN, Ediane Machado. A Influência do PIBID na Formação dos Acadêmicos de Química Licenciatura da UFSM. Revista Química Nova na Escola. vol. 34, n. 4, p. 167-172, nov. 2012. Disponível em: <http://qnesc.sbq.org.br/online/qnesc 34_4/02-PIBID-90-12.pdf>. Acesso em: 17 jul. 2013.

3. BRASIL. Ministério da Educação. Coordenação de Aperfeiçoamento Pessoal de Nível Superior - CAPES. Portaria no 096, de 18 de julho de 2013. Regulamento do Programa Institucional de Bolsa de Iniciação à Docência. 2013. Disponível em: <http://www.capes.gov.br/images/ stories/download/legislacao/Portaria_096_18jul13_AprovaRegulamentoPIBID.pdf>. Acesso em: 20 mar. 2016.

4. Ministério da Educação. Coordenação de Aperfeiçoamento Pessoal de Nível Superior - CAPES. Programa Institucional de Bolsa de Iniciação à Docência. 2008. Disponível em: <http://www.capes.gov.br/educacao-basica/capespibid>. Acesso em: 17 jul. 2013.

5.

Ministério da Educação. Escassez de Professores no Ensino Médio: Soluções Estruturais e Emergenciais. Relatório produzido pela Comissão Especial (CNE/CEB). Maio 2007. Disponível em: <http://portal.mec.gov.br/cne/arquivos/pdf/escassez1.pdf>. Acesso em: 15 jan. 2015.

6. _ _ Instituto Federal de Educação, Ciência e Tecnologia do Triângulo Mineiro - IFTM. Edital de seleção do Programa Institucional de Bolsas de Iniciação à Docência - CAPES / IFTM Edital n.o 04 / 2011 - Seleção de Alunos Bolsistas Para Projeto Pibid. Disponível em: 
<http://www.iftm.edu.br/proreitorias/pesquisa/pdf/EDITAL_IFTM_bolsistas_pibid_iftm_aju stado_em_03062011[1]\%20PUBLICADO.pdf>. Acesso em: 20 dez. 2014.

7. FELícIO, Helena Maria dos Santos. O PIBID como "terceiro espaço" de formação inicial de professores. Rev. Diálogo Educ., Curitiba, v. 14, n. 42, p. 415-434, maio/ago. 2014.

8. GARUTTI, Bianca Villamayor. O PIBID E SUA INFLUÊNCIA NOS ACADÊMICOS PARTICIPANTES. Universidade Federal do Mato Grosso do Sul. Campo Grande/MS. 2010. Disponível em: <http://www.pibid.ufms.br/TCC_Bianca_Garutti.pdf>. Acesso em: 17 jul. 2013.

9. GATTI, Bernardete A. ANDRÉ, Marli E. D. A. GIMENES, Nelson A. S. FERRAGUT, Laurizete. Um estudo avaliativo do Programa Institucional de Bolsas de Iniciação à Docência (PIBID). Fundação Carlos Chagas. Vol. 41- São Paulo: FCC/SEP, 2014.

10. GIL, Antonio Carlos. Como elaborar projetos de pesquisa. 4. ed. São Paulo: Editora Atlas, 2002.

11. GUIMARÃES, José Almeida. Apresentação. In: GATTI, Bernardete A. ANDRÉ, Marli E. D. A. GIMENES, Nelson A. S. FERRAGUT, Laurizete. Um estudo avaliativo do Programa Institucional de Bolsas de Iniciação à Docência (PIBID). Fundação Carlos Chagas. Vol. 41. São Paulo: FCC/SEP, 2014, p. 4-6.

12. LÜDKE, Menga e ANDRÉ, Marli E. D. A. Pesquisa em Educação: abordagens qualitativas. 2. ed. Rio de Janeiro: EPU, 2014.

13. MARCONI, Marina de Andrade e LAKATOS, Eva Maria. Fundamentos de Metodologia Científica. 5. ed. São Paulo: Editora Atlas, 2003.

14. STRAUSS, Anselm e CORBIN, Juliet. Pesquisa qualitativa - teorias e procedimentos para o desenvolvimento de teoria fundamentada. Tradução de Luciane de Oliveira da Rocha. 2. ed. Porto Alegre: Artmed, 2008. 